\title{
3D-Printed Landform Models
}

\section{INTRODUCTION}

Many Clever techniques to represent the undulations of the surface of the Earth have been documented in the pages of Cartographic Perspectives (Tait 2002; Jenny and Patterson 2007; Abplanalp 2013) and elsewhere (Imhof 1965; DiBiase et al. 1994). But at the end of the day, contour lines and other two-dimensional representations are abstractions that map viewers can interpret with varying degrees of success. Three-dimensional representations of landforms, on the other hand, are easy to understand, since we experience them as we experience the world around us. The following recipe is based on a workflow I developed to print landform models that can quickly and easily convey the shape of the land in educational settings, namely at wine-tasting sessions.

\section{A WORD ABOUT SUITABLE 3D PRINTERS AND SOFTWARE}

THE ONLY FULL-COLOR printer available in 2011 was the ZCorporation 650, which deposited a thin layer of gypsum plaster (also known as plaster of Paris) that was then sealed with a liquid binder. The model has since been rebranded as the ProJet 660 Pro from US-based 3D Systems.

At present I am working on another, smaller model to be printed on an Mcor IRIS printer from Ireland. These printers use reams of photocopier paper as the medium, work with inks in the CMYK color space, and coat the print so that it resembles plywood in look and feel. Their

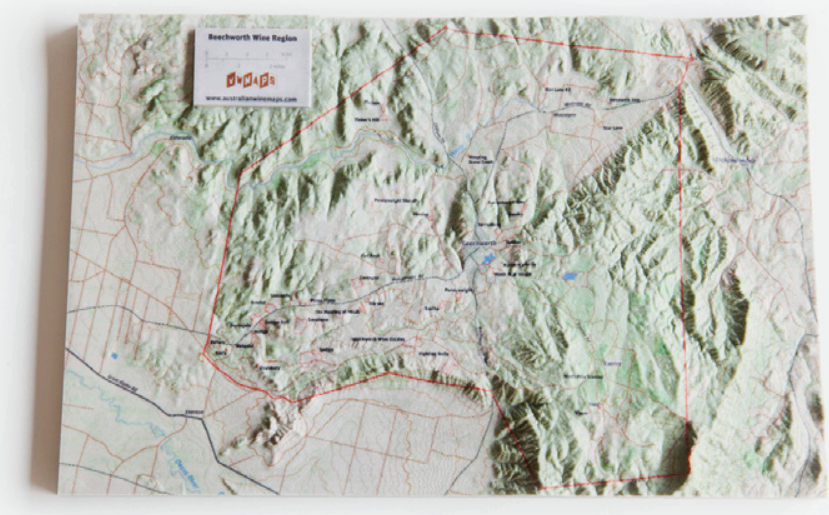

Figure 1. A model printed by vW Maps. More photographs are available at tinyurl.com/3dterrain. Photo by Bonnie Savage. main marketing pitch is the fact that the paper is inexpensive compared to the media used by other brands.

The following workflow uses Manifold System 8.0 with the Surface Tools extension for data compilation and DTM export, Adobe CS5 for creating and rasterising the map to be draped over the top of the model, and AccuTrans 3D from MicroMouse Productions for creating the 3D printer-ready file. Where I've capitalized ordinary words such as Drawing and Image, I'm referring to the meaning of the term within the software.

Much has been written, especially on CartoTalk (cartotalk.com), about Manifold software and how it hasn't been updated in many years. What's described here can surely be replicated in any other GIS software. But Manifold allows a user to easily merge and trim raster data and move quickly between raster data and imagery - two important traits in this exercise, as you'll see. Also, Manifold handles different projections and coordinate systems applied to different data sets particularly gracefully.

AccuTrans 3D excels at transformations between different 3D file formats. It's inexpensive, is updated regularly, and its developer is very responsive to requests and comments. Over the course of writing this paper the software 
has been upgraded quite a few times; the screenshots show how the user interface has changed. The functionality - at least of the small set of features I've needed and explored-has, however, not changed so as to make the older images in this article outdated.

\section{STANDARD 2D MAPMAKER'S WORKFLOW}

As YOU WOULD for any mapping project, begin by compiling data and projecting linework and a suitable DTM to your final map projection in Manifold. Meanwhile contact a 3D-printing service bureau to find out what printer is available and fits your needs and budget and then find out the final build size.

In Manifold, draw a blob around your area of interest as a new Drawing in order to define the final map area. If you want your model's edges to be aligned with north and south, then use Insert Box to draw a rectangle that covers the blob and then delete the blob from your drawing so only the rectangle remains. But if north doesn't have to be up, select the blob and use the Transform: Enclosing Rectangle option. Tweak the area so that the aspect ratio is roughly correct for the $3 \mathrm{D}$ printer's build area either by eye or by measuring the lengths of the rectangle. Keep this bounding rectangle in a safe place and don't change the map projection again.

Export the linework, including your bounding rectangle, and make a map draft in Illustrator or similar. Exporting a Layout Image onto $11 " \times 17$ " will give you a canvas that shows a little more than the map area. If you're happy with the result, you'll be able, in Photoshop, to easily crop the tabloid map to the ProJet 660 Pro's $10 " \times 15$ " build area, or that of the smaller IRIS. Note your final map scale.
Later you'll rasterize the AI file in Photoshop to create a JPG to be draped on the map. The manufacturer of the ProJet gives the printer's capabilities as $600 \times 540 \mathrm{dpi}$ but this is based on the printheads and not the medium which, to my eye, doesn't produce crisp detail much over 150dpi.

\section{CLEAN YOUR DTM}

If your DTM is assembled from multiple data sources, Manifold makes it very easy to compile these into the same layer through a simple copy and paste. Make sure, however, that you're adding pixels to the highest-resolution Surface so that you're never throwing away data.

Should your data have missing or incorrect height values, you can hunt these down and make up values using the Transformation "Threshold Lower." Zoom in tight to the erroneous cells, read the values of the neighboring cells, and type in a realistic value in the Transformation bar (permission to make up these data is granted under your cartistic license). Make sure that your View doesn't show relief shading, which Manifold does by default, because this will obscure which cells actually have the erroneous values.

\section{DO YOU WANT A CARTOUCHE?}

At This point I like to indulge my passion for postmodernism by dragging a renaissance-era convention into the present, and what better way than by writing "Martin fecit" under the map title on a 3D print? But whether you write this on the model in Trajan Pro or in Comic Sans, the cartouche will look funny if it's draped over steep terrain. A large water body might suit if you're not showing bathymetry or if the bathymetry is shallow, but if it has to be over hilly terrain you'll want a flat surface on the model.
So draw a rectangle in your Illustrator map in a suitable area. Using the map scale, calculate the size of the bounding rectangle if it were on the ground. For example, if you decide you can allocate $3 \times 2$ centimeters on your terrain model, you'll draw it as a Drawing in Manifold at $3 \times 2$ kilometers for a 1:100,000 map. Use a combination of Transform: Rotate, Transform: Move Horizontally, and Transform: Move Vertically to put the rectangle in the Drawing in about the right position relative to the terrain and bounding rectangle. 


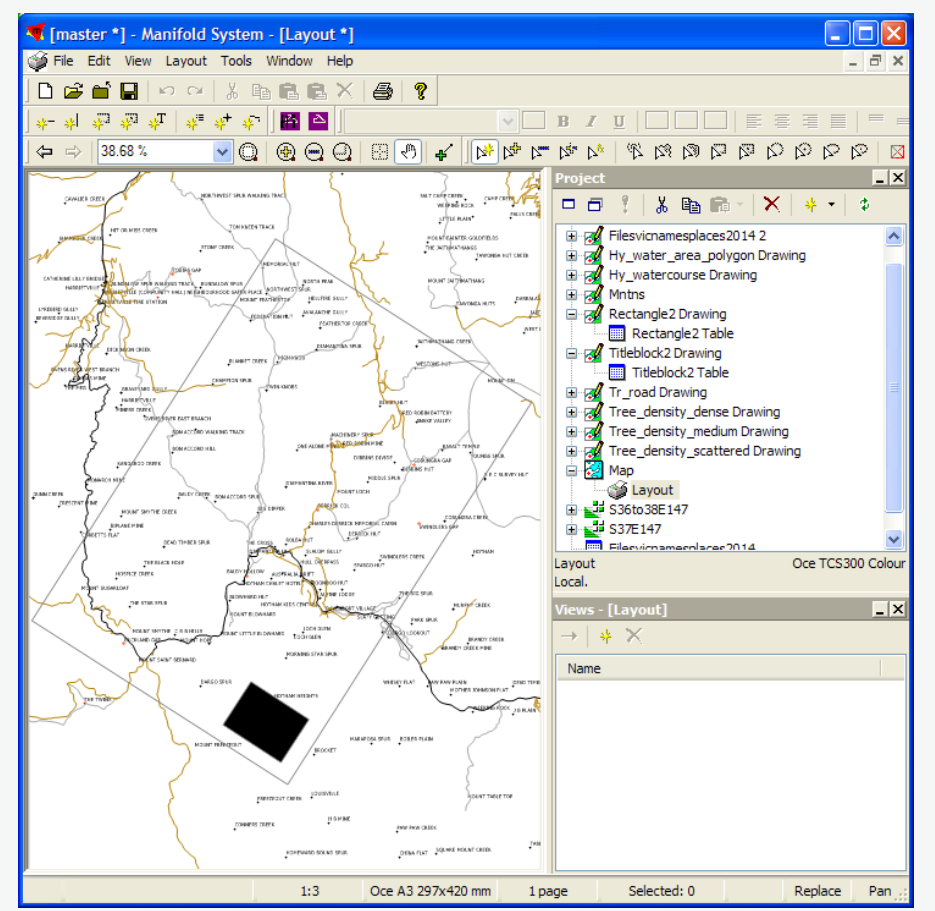

Figure 2. The black rectangle indicates the location of the title block.

Select the rectangle, make the Surface active, and select Surface $>$ Transfer Selection, Modifying your DTM Using the vector Drawing. Turn off the vector layer to confirm you've selected the pixels of the DTM that the title block will rest upon and make the DTM Surface layer active. Assign an appropriate $\mathrm{z}$ value once you've considered whether you want the title block to sit high like a plateau (as in Figure 1, above), whether it should be of an intermediate height among the hills, or whether it should sit in a depression in the land. Use Transformation: Threshold Lower and Transformation: Threshold Upper to type in the right height value, making sure you're only applying it to the "Selection in" your DTM layer.

Once the holes in the DTM have been patched and you've prepared an area for the title, then it's time to trim the DTM to your area of interest. First save your Manifold .map file so that you don't lose the master DTM. Make a new Map with your area of interest polygon and your DTM, making sure it's in your projection of choice. Select the rectangle and, as above, use Surface > Transfer Selection. Now make the Surface active and Select Inverse so that the heights outside of your subject area are selected. Delete, and now your 3D data set is ready. ${ }^{1}$ Export the

1. The Surface probably still has pixels outside your area of interest that will come through in AccuTrans 3D. My 3D operator has confirmed that these are easy to identify and trim.

\section{MIND YOUR PROJECTION}

Twenty years ago our GIS software could be a bit ham-fisted in its handling of data in different projections and coordinate systems. Things have changed since then and Manifold, in particular, handles data from various sources quite gracefully. The other side of the coin, however, is that the Manifold operator can get a little sloppy and careless, potentially resulting in output that's not necessarily in the right projection. Be careful to check the projection parameters as you proceed.

The first image below is the result of trimming the image, reprocessing it, and then exporting and re-importing a derivative. Note that the DTM data don't meet the outline of the area of interest, in red, because the projection of the DTM is wrong! The second is the result of reprocessing the DTM and then trimming it.
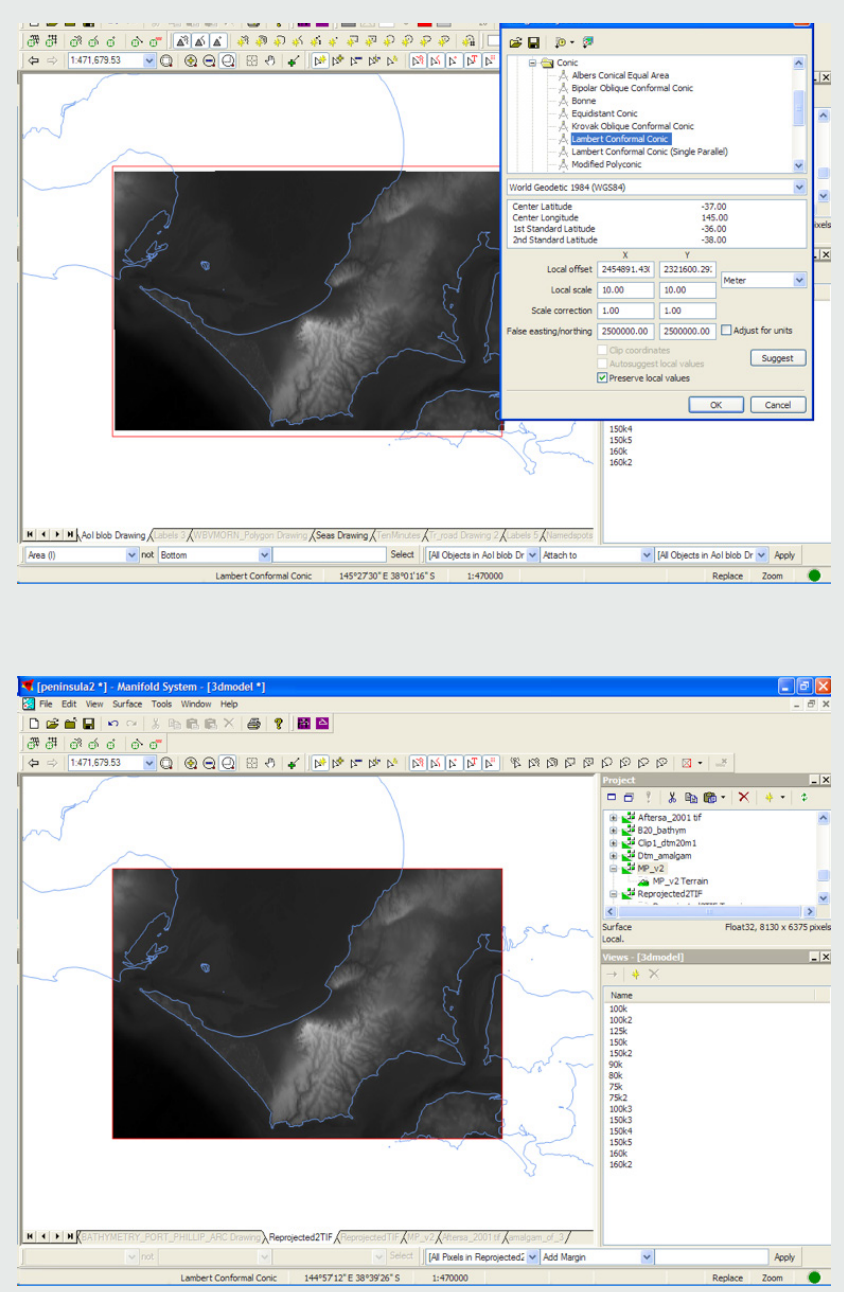
Surface as an ArcInfo ASCII Grid file, again making sure it has the right coordinate system and projection. To test that the projection is truly correct, export the trimmed DTM also as an image, either JPG or TIF. Bring that into your Illustrator file and if it's in the right projection, you'll be able to scale the image to fit the bounding box (see Mind your Projection, previous page).

Now turn off the Surface but keep the title block rectangle visible and export your Layout as another Image. Open this in Illustrator in order to make sure you put the elements that go inside the block in the right place on the Illustrator version of your map. Based on how this export lines up with your finished map, you may want to adjust the placement of your cartouche in Illustrator. You don't need to use this Manifold export in the finished map; after all, you don't want a neatline around your title block since it'll be quite apparent if your neatline doesn't perfectly line up with your tableland.

\section{FROM GIS TO REAL 3D}

Now in the Explorer window, change the file suffix of your ASCII Grid from .grd to .asc. Launch AccuTrans $3 \mathrm{D}$ and accept the default settings so that you're not throwing away any information.

After you've examined your 3D surface, exaggerate the elevation by clicking on the Change tab at upper right (Figure 4). At the bottom of the panel, change the Scale value from 1.0 to, for example, 2.5 and click Scale to see the resultant exaggerated $\mathrm{z}$ dimension. I've used 2, 2.5, and 5 for landscapes that were relatively flat and needed a little "lifting" (make sure your cartistic license hasn't expired). But watch out, because the effect is cumulative, so if you try 10.0, decide it's too much, and try to halve it by using 5.0, then your result will be an exaggeration of 50 ! No matter, just bring it back to where you started with 0.02 , the inverse of 50. Note that AccuTrans 3D has no Undo function.

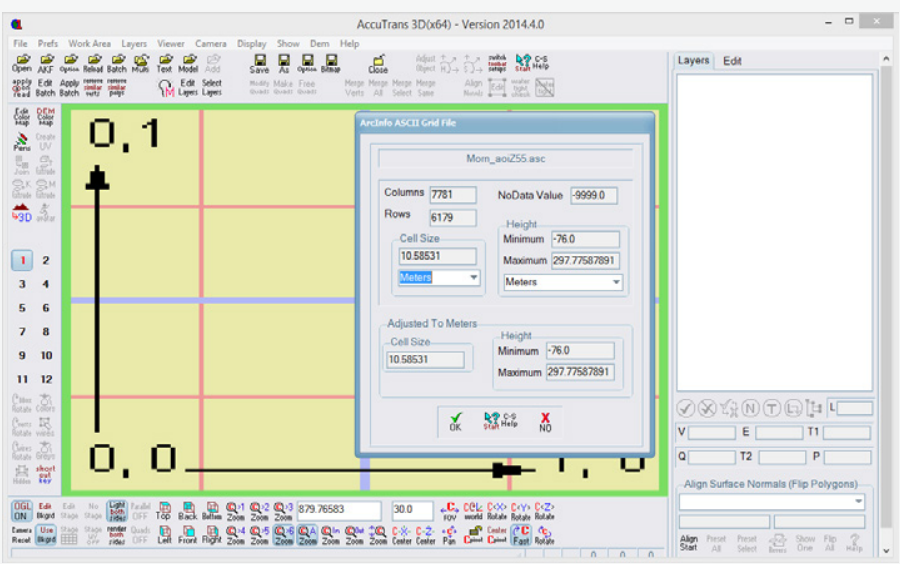

Figure 3. The amount of data, 48 million points, is acceptable and the heights above and below sea level, in meters, are plausible.

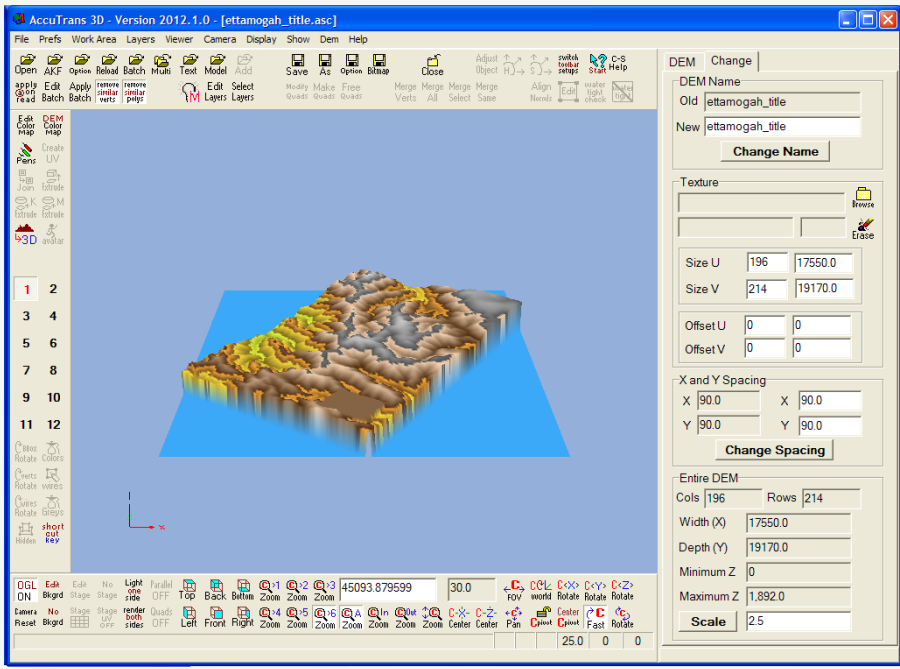

Figure 4. The Change tab at upper right lets you change the vertical exaggeration, at bottom right.

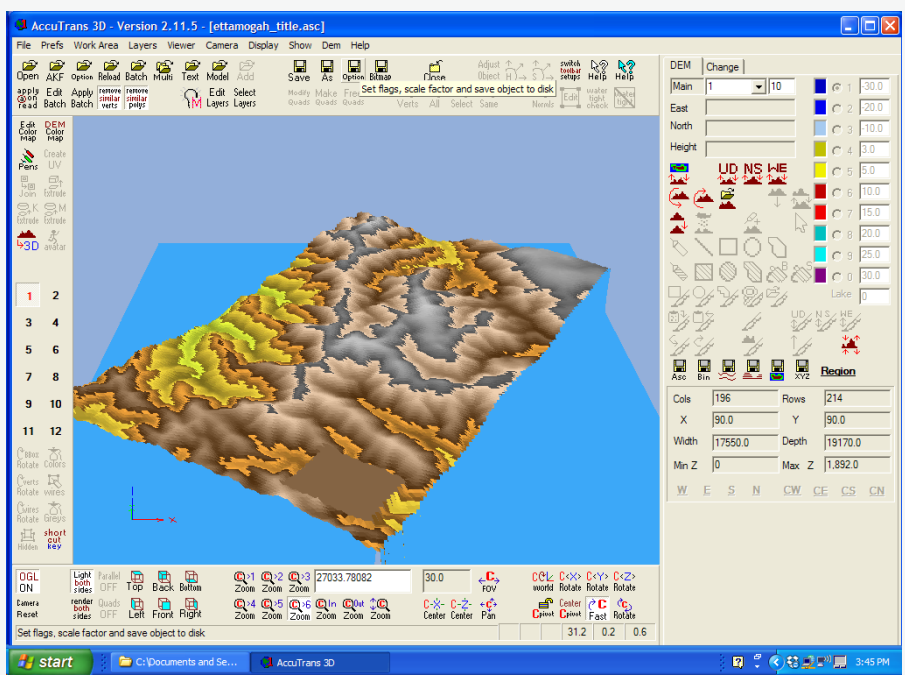

Figure 5. The "save with option" button, top center, will bring up a dialog window in which you can change parameters and save as another file format. 


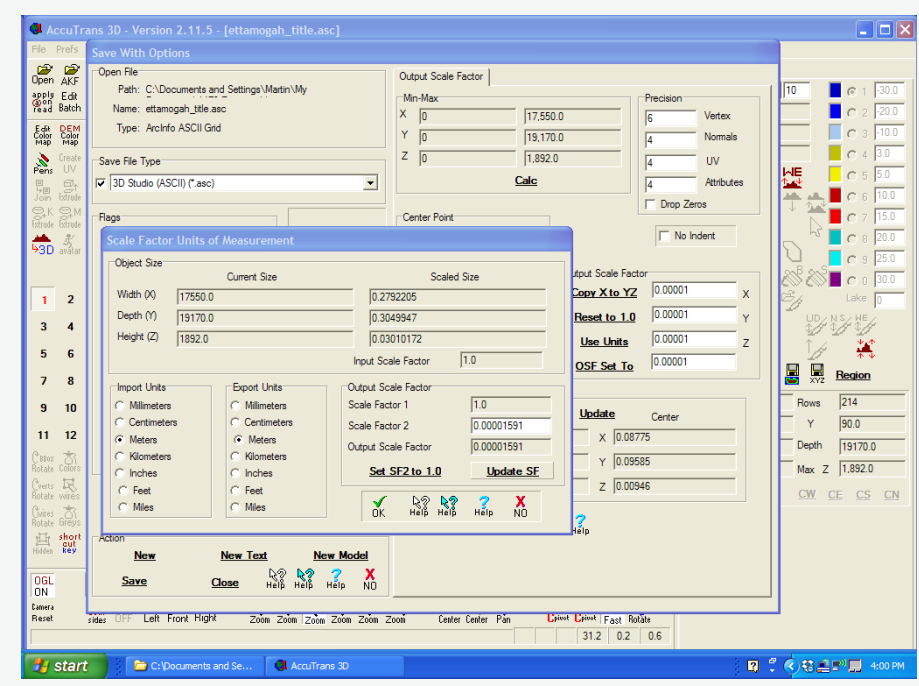

Figure 6. If your preferred map scale is 1:62,846-and whose isn't? -enter 0.00001591 as the Scale Factor 2.

3D printers are getting so big that they're printing houses these days (BBC News 2014). But even those printers won't be big enough to print our terrain, which is still at 1:1! So click the Option button with a floppy disk icon above it (Figure 5) and then the Output Scale Factor: Use Units button. I like to keep the import and export units in meters and then aim for the scaled size to be about 0.37 and 0.24 meters, or slightly smaller than the $10 " \times 15 "$ final build size of the ProJet 600 Pro. The Scale Factor 1 button doesn't like to be changed, but the Scale Factor 2 button brings the desired result when you enter the scale of the map as a ratio expressed as a decimal (Figure 6). Change your value here, Click Update SF and check that the Scaled Size measurements, in the upper part of the window, are about the right order of magnitude for your printer's printing bed-in other words, less than a meter. For a model at 1:100,000, use 0.00001 as the scale factor; for a 1:160,000 model, use 0.00000625. Press Save to exit the Save With Options window and save as a new file.

What format to export depends largely on what your service bureau wants. I've settled on the Wavefront (.obj) format, which seems to be space-efficient and is easily opened again by AccuTrans 3D to give you the peace of mind that you're sending a good file. I've had mixed success with VRML 2.0 (.wrl). Its advantages are that it allows you to map the JPG to the 3D surface and it's an old format for which you can easily find another software package to view the file. STL is the venerable "stereolithography" format from the days when this industry was for prototyping only. These files are huge and consequently both the service bureau and I have had trouble opening them.

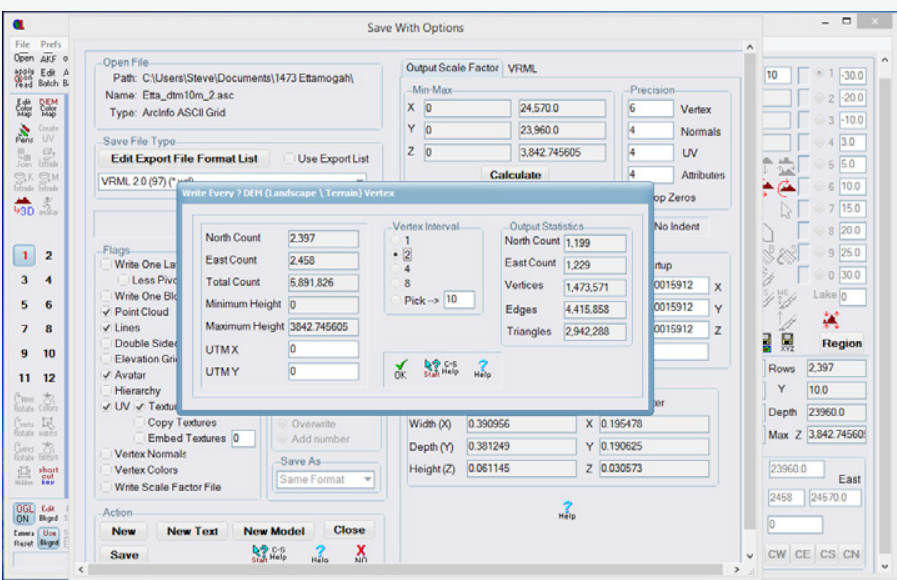

Figure 7. A vertex interval of 1 is lossless. $V I=2$ halves the number of points in both the $x$ and $y$ dimensions, so you're left with a fourth of the data.

Once you've selected your format, a new dialog box pops up in which you can reduce the number of vertices (Figure 7). Use a value of 1 to keep all data, use higher values to reduce the amount of vertices and therefore triangles in your mesh. As soon as you save, AccuTrans 3D writes the file but also leaves the dialog box open, so keep your eye on the spinning cursor to confirm the end of the writing of the file. Close to get rid of the dialog box, clearing your work, then open your new file. At this point AccuTrans $3 \mathrm{D}$ crashes a fair bit, especially if you've selected enormous .stl or .wrl files. Reducing the number of vertices by a factor of two as in Figure 7 above was required to get AccuTrans 3D to open the VRML file.

Your printer may want you to extrude the surface, which is presently not a $3 \mathrm{D}$ volume but a 2 -and-a-half-dimensional surface. Use the Extrude Pseudo 2d Surface button

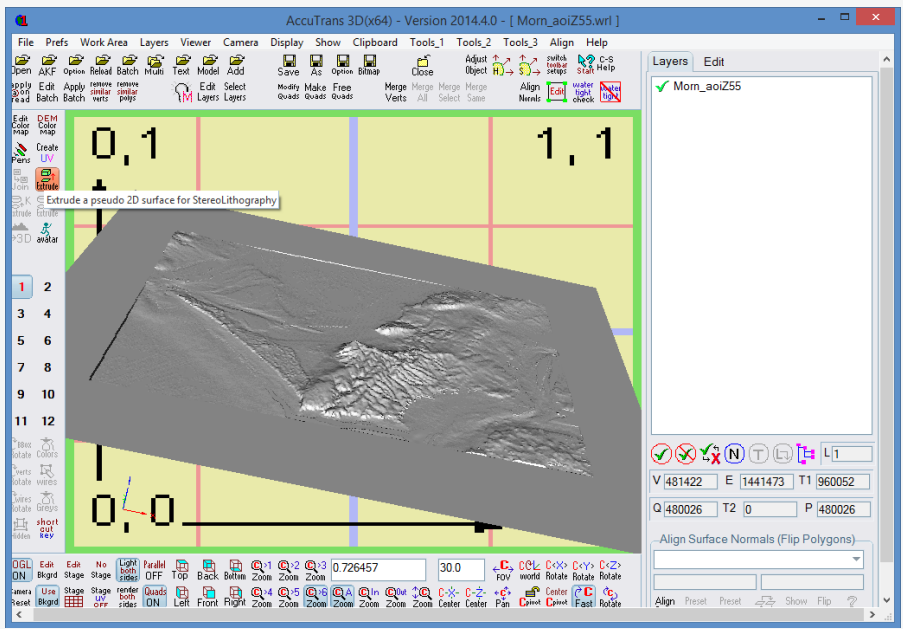

Figure 8. To avoid a wafer-thin model, extrude your surface. 
at left and add a dimension (Figure 8). I chose .01 as the Thickness (Figure 9) so that a $1 \mathrm{~cm}$ thickness would be applied. Keeping the model thin keeps costs down since you're paying by the amount of material printed; $1 \mathrm{~cm}$ provides some strength so that the model isn't brittle.

I have also stipulated a flat bottom in the past but it's unclear from the printer whether that's helpful or not. Click Extrude and then the OK button.

As a final and maybe optional step, you can map the JPG you created to the DTM as long as it's a VRML file. It's much more satisfying looking at your model in the AccuTrans 3D environment with your pretty map on it than without it. But this step isn't essential and if your rectangle isn't oriented due north/south, it's downright impossible, as far as I can tell. Click Change tab and select the Texture button and browse to find your JPG.

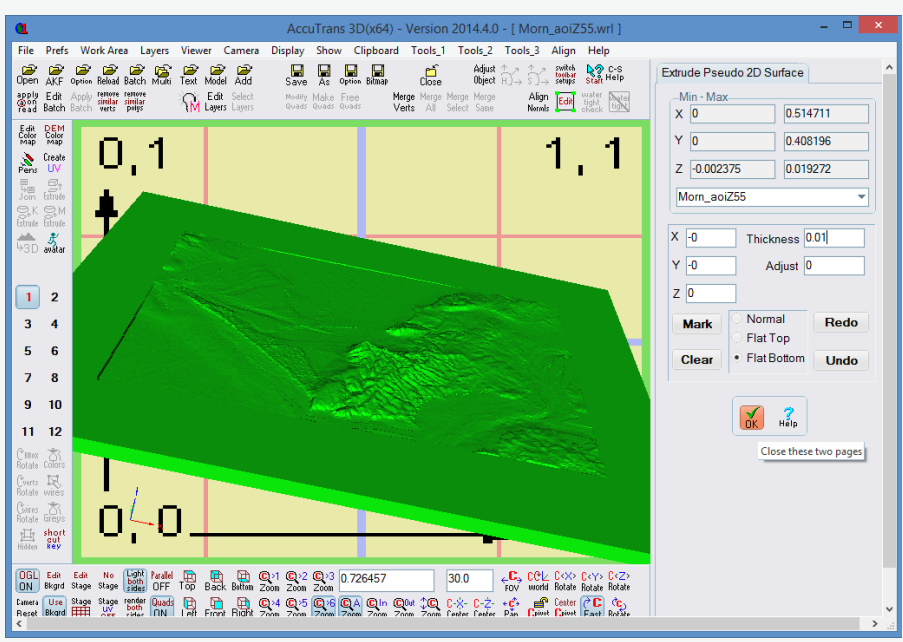

Figure 9. Applying a thickness of 0.01 meters incurs cost but gives the model strength.

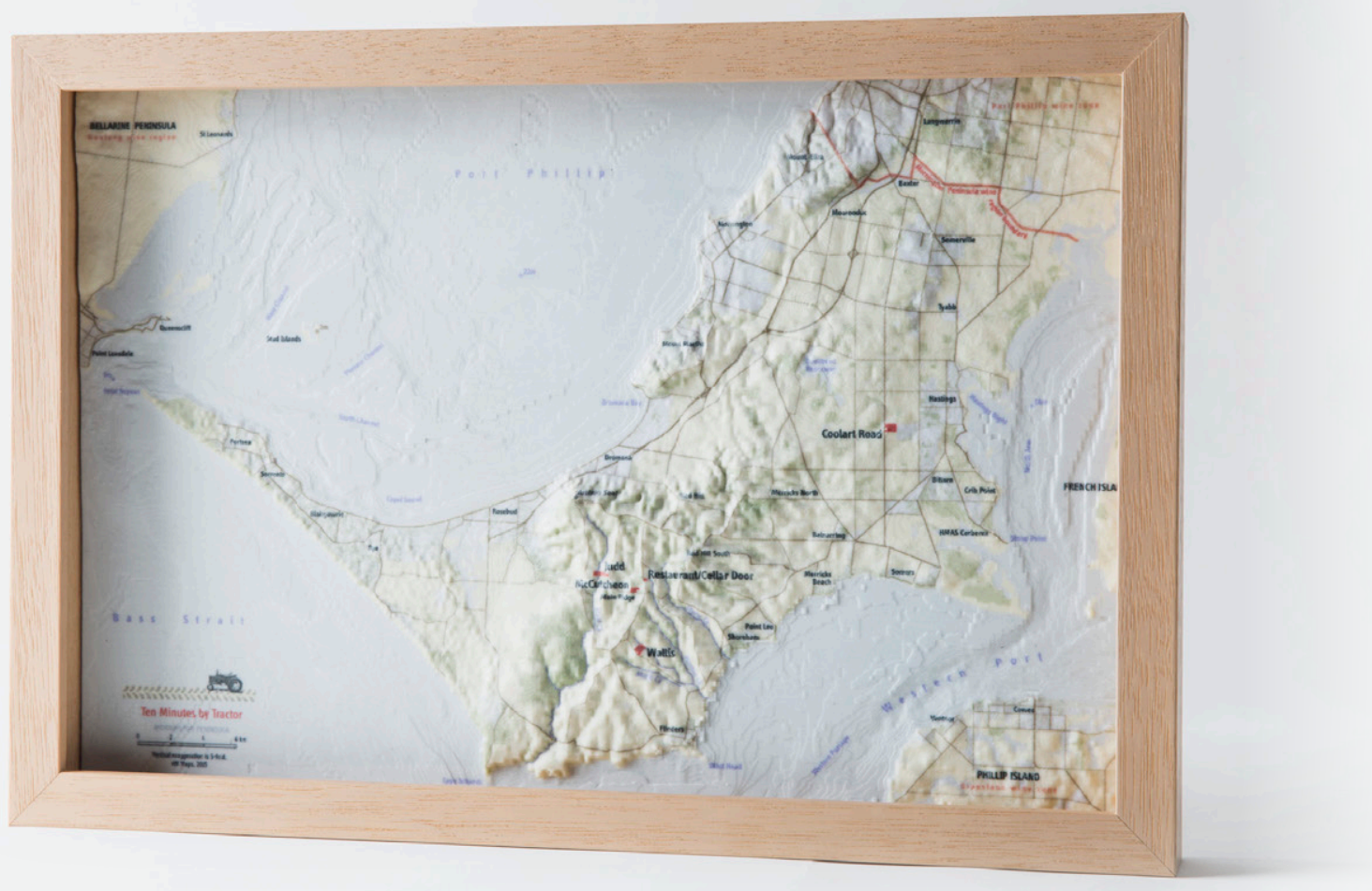

Figure 10. Ripe for research: How should we use relief shading and hypsometric tinting? Photo by Bonnie Savage. 
Many of us have fond memories of a visitor center with a large, 3D terrain map probably made of plaster or concrete. Will 3D printing spawn a new era of such interpretive maps that use the DEM data that are now so readily available? Not too soon, is my prediction, not just because the build sizes of full-color printers are small, but also because costs are high.

The tools are still a challenge, too. I was surprised to see, when sitting with a $3 \mathrm{D}$ printer operator while he was preparing my files for printing, how primitive the software is. Aligning the JPG to the terrain is done by eye rather than by snapping vertices. On the cartographic side of things there are challenges, too. AccuTrans 3D doesn't support map projections, but luckily its programmer is dedicated and offers great customer support for his remarkable software. And this territory is still new enough that the service bureaus are accustomed to spending time on our files, probably because they're not experienced enough with terrain models to be able to specify what parameters they prefer. Don't be surprised if they answer your questions with "just give me what you have and I'll make it work."
Further research from the academic community would be very welcome. For example, is cognition really improved with terrain models rather than maps with contour lines? And in terms of model design, should important labels be written onto flat sections of the model with a single $\mathrm{z}$ value, as I advocate for cartouches? What vertical exaggeration is appropriate, and how does that change depending on the map scale and the local relief of the subject area? Does the elevation in the model effectively explain the terrain, or should the water be colored with bathymetric tinting? Similarly, do the hills and mountains come alive under the lights shining on the model, or should the cartographer paint relief shading on the surface? And rather than simply representing the surface of the earth, are 3D models of space effective at showing the distribution of quantitative phenomena?

Costs will come down, software will improve, and future GIS packages will probably support 3D printing file formats the way Photoshop CC can now export to the STL format. But in the meantime, good luck with printing your terrains.

\section{ACKNOWLEDGEMENTS}

Thanks to Wayne Hogue at MicroMouse Productions, Simon Bartlett of Objective3D, and Nasser Samman at 3D Systems.

\section{REFERENCES}

Abplanalp, Kelly. 2013. "Experimental Terrain

Representation.” Cartographic Perspectives 76: 77-78. doi: 10.14714/CP76.1249.

BBC News. 2014. "How Dutch team is 3D-printing a full-sized house." May 3. http://www.bbc.com/news/ technology-27221199.

DiBiase, David, T. Paradis, and J. L. Sloan II. 1994. "Weighted Isolines: An Alternative Method for Depicting Statistical Surfaces." The Professional Geographer 46 (2): 218-228. doi: 10.1111/j.0033-0124.1994.00218.x.
Imhof, Eduard. 1965. Kartographische Geländedarstellung. Berlin: de Gruyter.

Jenny, Bernhard and T. Patterson. 2007. "Introducing Plan Oblique Relief.” Cartographic Perspectives 57: 21-40. doi: 10.14714/CP57.279.

Tait, Alex. 2002. "Photoshop 6 Tutorial: How to Create Basic Colored Shaded Relief." Cartographic Perspectives 42: 12-17. doi: 10.14714/CP42.550. 